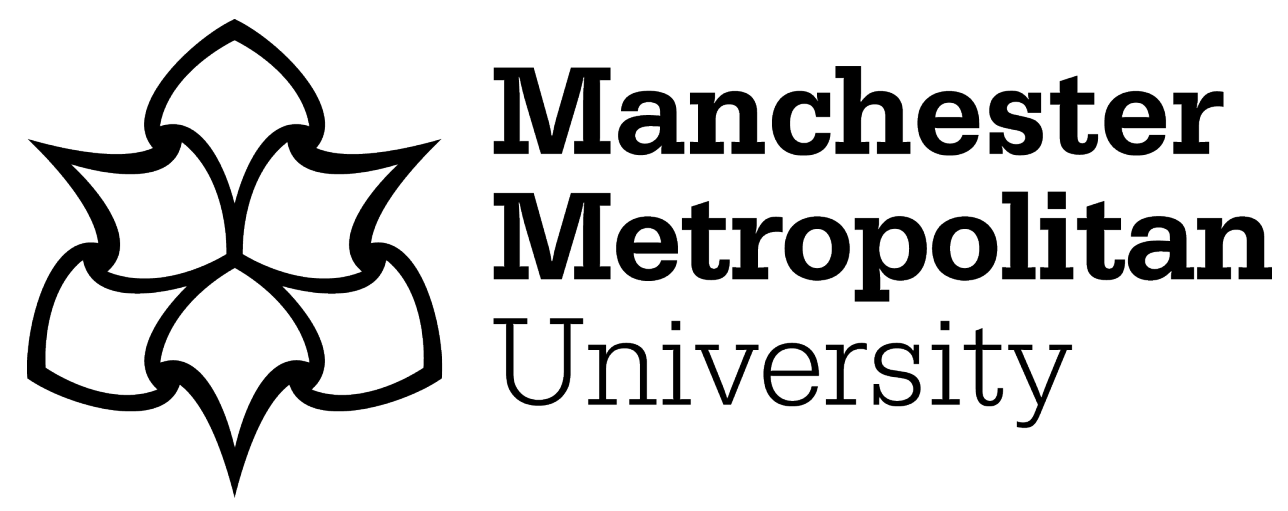

Hulme, Moira ORCID logoORCID: https://orcid.org/0000-0002-4095-3880, Wood, Jeffrey and Shi, Xin (2020) Measuring up? Metrics and research assessment in UK teacher education. Journal of Education for Teaching, 46 (2). ISSN 0260-7476

Downloaded from: https://e-space.mmu.ac.uk/623669/

Version: Accepted Version

Publisher: Taylor \& Francis (Routledge)

DOI: https://doi.org/10.1080/02607476.2020.1724658

Please cite the published version 


\section{Measuring up? Metrics and research assessment in UK teacher education}

This paper offers a multi-dimensional analysis of publication outputs from teacher education research published in the UK between 2000 and 2013. The analysis draws on a sample of 727 articles published in 39 journals. Using metrics data extracted from Elsevier's Scopus database, the analysis outlines the distribution of outputs and explores characteristics associated with productivity and influence. Conceptual and methodological issues with the enumeration of research quality and impact are identified, including quality criteria, citation practices and coverage in leading bibliometric databases. Several contextual factors are taken into consideration. These include author affiliation at the time of publication, university research ranking, Education subject ranking and the size of intake for programmes of initial teacher education. The analysis confirms an association between publication productivity and institutional type, with an inverse relation between large-scale engagement in the practices of teacher education (represented by student numbers) and the production of research on teacher education that is judged to be of high quality. This has implications for how the activities of university Schools of Education are valued and the prospects for research-informed teacher education in the UK.

Keywords: bibliometrics, scholarly productivity, research assessment, teacher education.

\section{Introduction}

The last decade has seen the spread of quality-related or performance-based research funding systems in higher education. Following the introduction in the United Kingdom of the Research Assessment Exercise (RAE) (now Research Excellence Framework, REF) in 1986, national research evaluation systems have been introduced in Australia (Excellence in Research for Australia, ERA), New Zealand (Performance-Based Research Fund, PBRF), Portugal (the Fundação para a Ciência e aTecnologia, FCT), Italy (Evaluation of Research Quality, VQR), the Netherlands (Standard Evaluation 
Protocol, SEP), Denmark (Bibliometric Research Indicator, BFI) and Hong Kong (Research Assessment Exercise, RAE) (Grant et al., 2010; Hicks, 2012). In straitened conditions of public accountability, national funding bodies and research policy analysts are attracted to citation-based performance analysis alongside more established (if still contested) indicators of research performance (Colwell et al., 2012).

Irrespective of whether national protocols favour peer review-based judgements or citations, academic reward systems influence how researchers and research managers respond to performance indicators. The routine use of bibliometric indicators is now established within evidence-based institutional systems for research management and faculty appraisal. Academics are required to deposit publications in institutional repositories. Productivity in terms of publication is embedded in workload modelling. Academic work is audited through a range of accounting practices that include periodic time allocation surveys, teaching evaluations, income generation, programme recruitment and conferment targets (Menter et al., 2012). Burrows (2012, p.359) has described a regime of 'quantified control', noting that there are 'over 100 different (nested) measures to which each individual academic in the UK is now (potentially) subject'. While demonstrating ambivalence towards bibliometric indicators, performance-aware scholars nevertheless often use the new metrics in the construction of academic value in tenure and promotion dossiers.

The rise of bibliometrics in academic assessment is contested. Evaluation regimes have a potentially distorting influence on academic work, encouraging strategic behaviour such as goal displacement (where the measure becomes the goal) and task reduction (encouraging individual mono-disciplinary productivity) (Butler, 2007). The impact of such moves may be experienced differently in terms of gender, class, ethnicity, career stage and generation (Burrows, 2012). Critics argue that an emerging 
'economy of publications and citations' (Larsson 2009, p.34) has contributed to the promotion of self-regulating, entrepreneurial and competitive research identities, and a hierarchy of languages and theories that favours the global North (Nylander et al., 2013; Mignolo, 2013). Prospects for publication increasingly shape the processes of knowledge production. Although publication, citation and dissemination practices vary between disciplines, bibliographic analysis has become embedded in the life-world of the university (Hicks, 2013; Thelwall \& Delgado, 2015).

Given the institutionalisation of bibliometrics within regimes of academic accountability, there has been little corresponding interrogation of bibliographic databases to explore the social dynamics of knowledge production in Education. Concerns about the appropriate use of standardised assessment metrics in disciplines beyond science and medicine may account for the paucity of studies that have reviewed publication outputs in education studies or the educational sciences (Diem \& Wolter, 2013; Gogolin et al., 2014). There are even fewer publication analyses in the sub-field of teacher education research (Murray et al., 2008; Avalos, 2011; Cochran-Smith \& Villegas, 2015). This research addresses this omission at a time of uncertainty for teacher education as a field of enquiry and programme of professional preparation located in universities. One of the espoused aims of metrics-based assessment is the improvement of research quality. Building and sustaining research capacity in teacher education is recognised as an enduring challenge in the UK and internationally (Beauchamp et al., 2015; BERA-RSA, 2014). Prospects for research-informed teacher education in England are adversely affected by contracting sources of funding for applied and practice-based research, variable levels of institutional support for teacher educators to develop a research orientation to their work, and recent Government policy direction that has accelerated moves towards school-led teacher education, including 
teacher apprenticeships (Whitty et al., 2012; Oancea \& Mills, 2015; McNamara \& Murray, 2013).

This article offers a reflexive engagement with processes of metrification and considers the consequences of such moves for the work of teacher education in the academy. It offers a descriptive analysis of fourteen years of publication, covering two national research assessments (RAE 2008 and REF 2014). In mapping historical patterns of productivity, the analysis provides insight into the development of research capacity in an emerging field. The following section offers an account of the guiding questions, data sources and analysis strategy. Summary findings are presented in the third section. The conclusion returns to the policy issues raised by the analysis and identifies future directions for mapping the field.

\section{Study design}

This study builds on the capacity building activities of the Teacher Education Group (TEG) which produced an annotated database of research in teacher education undertaken in the UK and published between 2000 and 2008 (Murray et al., 2008; Menter et al., 2010). The creation of the TEG bibliography was funded by the British Educational Research Association (BERA), the Universities Council for the Education of Teachers (UCET), and the Education Subject Centre of the Higher Education Academy (ESCalate). The TEG bibliography was not intended for evaluation purposes. It was established by the research community to enhance the visibility of UK research in teacher education to enable its interrogation and use by teacher educators. Each retrieved research article was tagged to identify the core research themes and methodological approach (Menter et al., 2010). The study reported here uses the same list of core journals (appendix 1) and retrieval methods to extend the mapping of 
research to 2013. This second survey of the field does not address themes or methods but uses a range of metrics to explore potential influences on publication in the teacher education research community. The following questions were posed:

- How is productivity distributed among lead authors?

- How is productivity influenced by institutional affiliation?

- How is productivity influenced by region?

- What is the association between productivity and the research profile of the institution?

- How is productivity linked to institutional involvement in initial teacher education?

Productivity is operationalised as authorship of articles published in core journals in the field of teacher education. This operationalisation excludes other forms of scholarly communication including alt-metrics (scholarly activity using online tools and environments e.g. twitter, blogging, social reference managers), which may be more susceptible to inflation through manipulation (Barnes, 2015).

In total, 727 articles published between 2000 and 2013 were selected for inclusion from 39 peer-reviewed mono-lingual (English) journals. In all cases at least one of the authors was employed by a higher education institution located in the UK at the time of publication. The analysis is restricted to outputs published in predominantly UK journals and excludes outputs by academics working in the UK and selecting international journals beyond the UK. Throughout this article 'author' refers to lead or first author. As conventions vary concerning the order of co-authors, fractional counting of co-author contributions was discounted. 
The commercial citation database, Scopus from Elsevier, was the primary source of data. Publication and citation records vary between databases (Sarkosy et al., 2015; Hicks, 2013). Of the 216 education journals listed in Web of Science, 194 are published in English and 81 are registered in the UK. However, of the 39 journals identified as important by the Teacher Education Group, only 19 are registered with Web of Science as core journals containing the most significant scholarly outputs. Scopus includes 37 of the 39 TEG journals but coverage is incomplete. For the period 2000-2013, 23 of the 39 TEG sources are not covered completely (missing issues/years). Where articles were not included in the Scopus database, citation data was extracted from: (1) publisher databases; 2) ResearchGate; or (3) Google Scholar for articles published in the Scottish Educational Review. It is noted that citation counts in Google Scholar tend to be higher than those recorded in conventional citation indexes (Kousha \& Thelwall, 2007). Author profiles were screened using university faculty profiles to identify similar names, change of name and misattribution. The citation count for individual articles ranged from 0 to 259 citations and is used as a proxy indicator for the response to a publication within the academic community. Citation can be influenced by visibility and recency of publication (the 'immediacy effect'). The most highly cited articles were published before 2010. Of course, there are a variety of motives for citing (which includes self-citation) not all of which indicate high quality research. As Lindgren (2011, p.8) observes, motives for citing or not citing include many that 'may be characterized as personal, self-serving or even political rather than professional or scholarship-serving'. Bias, amplification and invention can produce unfounded authority claims (Greenberg, 2009).

In addition, the current $h$-index of each first author was extracted from Scopus. In Scopus a researcher with an $h$-index of $n$ has published $n$ papers, each of which has 
been cited $n$ times since 1996. This measure minimises distortion arising from a single highly cited article, although has weak discriminatory power (Barnes, 2014). While the measure aims to avoid equating raw productivity rates with assumed quality, a low index may be attributed to a researcher with higher scientific impact (Gingras, 2014). In Scopus, the $h$-index is not a static value but is calculated each time a set of results is created. The $h$-index data for this study was extracted in February 2016. Whilst failure to be sensitive to the order and number of co-authors is often cited as a limitation of this metric, in this study $h$-index enables the analysis to extend beyond papers where the author is named as first author. The $h$-index for first authors ranged from 0 to 23 .

Two additional proxy measures for research quality are used: journal ranking and the citation impact attributed to individual articles. Article level metrics are included to mitigate the limitations of appraising articles by the impact factor of the journal in which they appear. The 2014 SCImago Journal Rank was used for all journals covered in Scopus i.e. the average number of weighted citations received in 2014 by the documents published in the selected journal in the three previous years. Journal ranking scores ranged from 0.12 (lowest) to 1.77 (highest). Where available, Scopus FieldWeighted Citation Impact (FWCI) measures were identified for individual articles. In Scopus, the FWCI is the ratio of the total citations actually received and the total citations that would be expected based on the average of the subject field (or field norm), in this case 'educational research' e.g. a FWCI of 1 means that the output performs just as expected for the global average. FWCI measures were available for 446 of the 727 articles.

A number of contextual measures ground the analysis in the field of teacher education in the UK. In addition to article and author metrics, consideration was afforded to author affiliation at the time of publication. This is significant given the 
history of teacher education in the UK and the varying priorities, mission and reward structures among higher education institutions in relation to professional preparation and research activity (Menter, 2011; Beauchamp et al., 2015). Higher education institutions were categorised as pre-1992 (including the research-intensive Russell Group), first wave post-1992 (former polytechnics), and second wave post-1992 (including former colleges of higher education). The Russell Group is a self-selecting group of 24 research-intensive universities (15\% of UK HEIs) that receives $68 \%$ of the total quality-related research funding allocated by the UK research councils (The Russell Group of Universities, 2017). Post-1992 HEIs are 'new' or modern universities that include former polytechnics, university colleges and colleges of higher education granted degree-awarding status either after 1992 (first wave) or in the 21st century (second wave). As the period of active publication encompasses 2000-2013, a small number of authors identify colleges of higher education as their affiliation prior to subsequent universitisation or merger. In REF 2014, 57 submissions were made to the Education Unit of Assessment (UoA 25) from HEIs involved in initial teacher education in the UK, including one college of higher education (REF, 2014).

To explore the relationship between institutional involvement in teacher preparation and research performance, approved student intakes for teacher education programmes were compared with outcomes achieved in the UK research assessment process. The total number of core first year trainees (undergraduate and postgraduate courses in initial teacher training) according to the 2015/16 Teacher Census, excluding the employment-based Teach First Leadership Development Programme, is used to indicate HEIs involvement in teacher preparation in England. Approved intakes to ITE programmes in 2015/16 in the devolved nations were obtained from the Scottish Funding Council, Higher Education Funding Council of Wales and the Department of 
Education Northern Ireland. It should not be assumed that publishing academics employed within Schools of Education that are involved in ITE are engaged in teacher education or self-identify as teacher educators.

The analysis in regard to the two UK research assessments - RAE 2008 and REF 2014 - excludes papers authored by lead authors in jurisdictions not participating in the UK research assessment. Comparisons have been avoided between mismatched data, for example between citations for individual articles and peer judgements that pertain to groups of researchers within Schools of Education made by an expert panel. 2008 RAE and 2014 REF judgements are based on a selection of research (up to four outputs per academic) submitted for assessment from across the diverse fields of pure, applied and practice-based education research.

To provide some contextual information on the research environment in which the articles were generated, data on the proportion of staff returned in the 2014 research assessment was used. For each HEI provider the number of full-time equivalents (FTE) of academic staff eligible for return in the Education Unit of Assessment of the REF 2014 was compared with the number of academics actually returned (HESA, 2015). Eligible staff are those holding a 'research' or 'teaching and research' contract. This measure thus excludes the growing number of academic staff employed on 'teaching only' contracts, particularly in old universities (Oancea \& Mills, 2015). The inclusion of the proportion of staff returned helps to provide a more nuanced understanding of 'research power'. In REF 2014 'research power' is the overall Grade Point Average (range 0-4) multiplied by the full-time equivalent number of researchers submitted. Of course, HEIs may deploy different strategies in locally decided criteria for REF inclusion e.g. quality thresholds. 
Citation data was prepared in Microsoft Excel and analysed using the Statistical Package for the Social Sciences (SPSS).

\section{Findings}

\section{RQ1. How is productivity distributed among lead authors?}

Productivity in teacher education research rose steadily between 2003 and 2007, ahead of the UK 2008 Research Assessment Exercise (figure 1). While the volume of articles rose overall, author productivity and article reception (FWCI \& $h$-index) are patterned in particular ways.

Figure 1. Number of journal articles per year




Just under half the researchers in this sample (48\%) published just one article where they are named as first author over the period 2000-2013 (see Table 1). Eighteen per cent of (first) authors published five or more papers.

Table 1. Number of papers per author: frequencies and percentages

\begin{tabular}{|c|c|c|c|c|c|c|c|c|c|c|}
\hline & \multicolumn{10}{|c|}{ Number of papers published by an author over the 2000-2013 range } \\
\hline & 10 & 9 & $\underline{8}$ & $\underline{7}$ & $\underline{6}$ & $\underline{5}$ & $\underline{4}$ & $\underline{\mathbf{3}}$ & $\underline{\mathbf{2}}$ & $\underline{1}$ \\
\hline $\begin{array}{l}\text { Author Count } \\
\text { Cumulative Author }\end{array}$ & 2 & 2 & 2 & 2 & 4 & 9 & 12 & 20 & 65 & 352 \\
\hline Count & 2 & 4 & 6 & 8 & 12 & 21 & 33 & 53 & 118 & 470 \\
\hline & \multicolumn{10}{|c|}{$\begin{array}{c}\text { Total number of papers for the authors in each frequency of } \\
\text { publication bracket }\end{array}$} \\
\hline Sum of papers & 20 & 18 & 16 & 14 & 24 & 45 & 48 & 60 & 130 & 352 \\
\hline Cumulative no papers & 20 & 38 & 54 & 68 & 92 & 137 & 185 & 245 & 375 & 727 \\
\hline $\begin{array}{l}\text { Percentage of papers } \\
\text { Cumulative }\end{array}$ & 2.75 & 2.48 & 2.20 & 1.92 & 3.30 & 6.19 & 6.61 & 8.22 & 17.91 & 48.42 \\
\hline Percentage & 2.75 & 5.23 & 7.43 & 9.35 & 12.65 & 18.84 & 25.45 & 33.67 & 51.58 & 100.00 \\
\hline
\end{tabular}

There is a broadly equitable gender balance in terms of publication productivity. Three hundred and seventy two (51\%) were attributed to female lead authors and 355 papers $(49 \%)$ to male lead authors. The selection overall included 470 lead authors, of these 253 authors were female and 217 male (some lead authors contributed multiple papers). This is broadly consistent with the gender composition of Schools of Education. (HESA, 2015). No consideration is made here of age, role and career stage, which are important variables influencing research productivity (van Arensbergen et al., 2012). Analysis of the relative number of lead authors of each gender as a proportion of the total number of academics of each gender in full-time employment using Chi-squared analysis shows that there is no significant association between gender and whether an academic is a lead author on a paper $\left(\chi^{2}(1, \mathrm{~N}=6966)=0.03, p=.865, \mathrm{Phi}=.002\right)$. 


\section{RQ2. How is productivity influenced by institutional affiliation?}

The analysis demonstrates a strong association between levels of productivity and institutional type. In order to examine this, we compared the total number of publications for each university (e.g. Manchester Metropolitan University had sixteen publications in the period) by university type (e.g. Manchester Metropolitan University is a post-92) using a non-parametric Kruskal-Wallis test. This showed a significant difference $\left(\chi^{2}(3, N=95)=19.32, p<.001\right)$ (see figure 2$)$.

Figure 2. Median number of publications for each university by university type

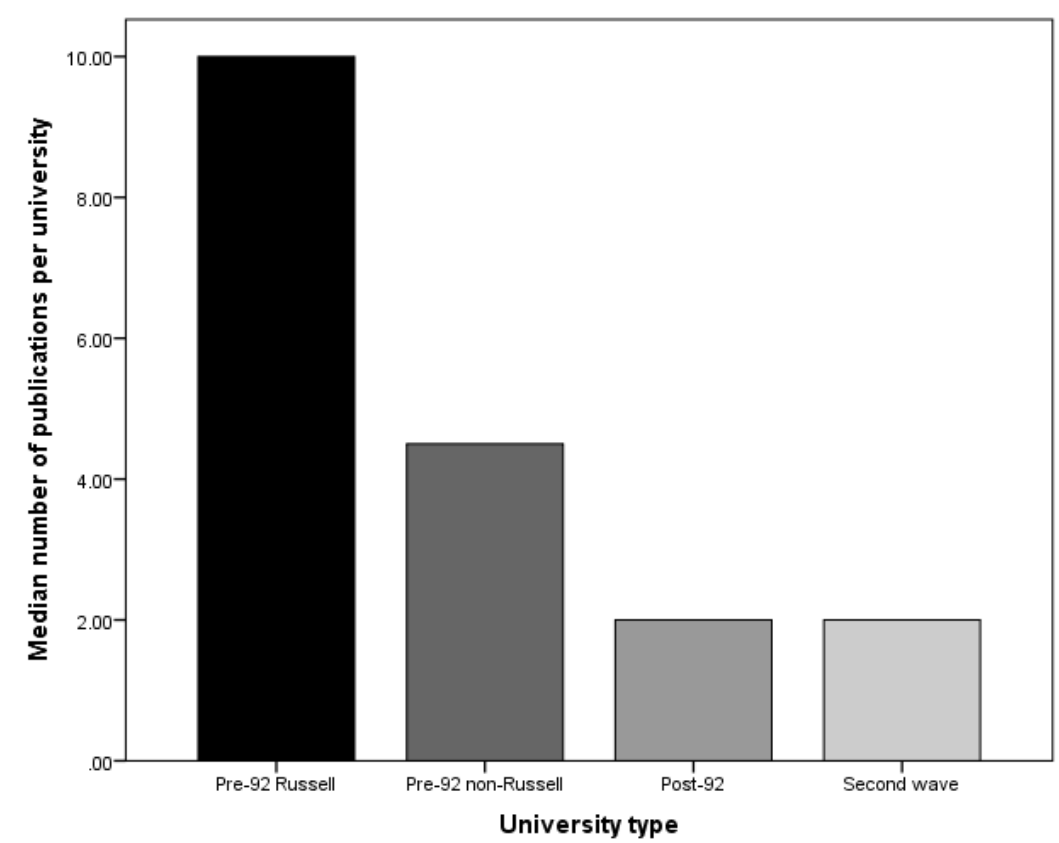

In order to explore this further six pairwise comparisons using Mann-Whitney U were conducted using a Bonferroni corrected value of $p=.008$. These showed no difference in the total number of articles produced at Russell Group than other pre-92 universities $(\mathrm{U}=147.00, p=.065)$. However, Russell Group universities did publish more articles than the post-92 $(\mathrm{U}=155.00, p<.001)$ and the post-92 second wave universities $(\mathrm{U}=$ $65.50, p<.001)$. Pre-92 non-Russell group universities showed no difference with the post-92 universities $(\mathrm{U}=235.50, p=.057)$ or second wave universities $(\mathrm{U}=126.00, p$ 
$=.070)$. Finally, the post-92 universities also showed no difference in the number of publications to the second wave universities $(\mathrm{U}=320.00, p=.955)$.

Academics employed at pre-1992 universities at the time of publication authored articles with the highest FWCI (figure 3). Indeed, a Kruskal Wallis test, with university type (Pre-92 (Russell), Pre-92 (non-Russell), First wave post-92, Second wave post-92) as the independent variable and FWCI as the dependent variable, shows a significant relationship between university type and FWCI $(\chi 2(3, N=438)=9.63, p=.022)$.

Figure 3. Relationship between author affiliation (university type) and Field-Weighted Citation Impact of articles

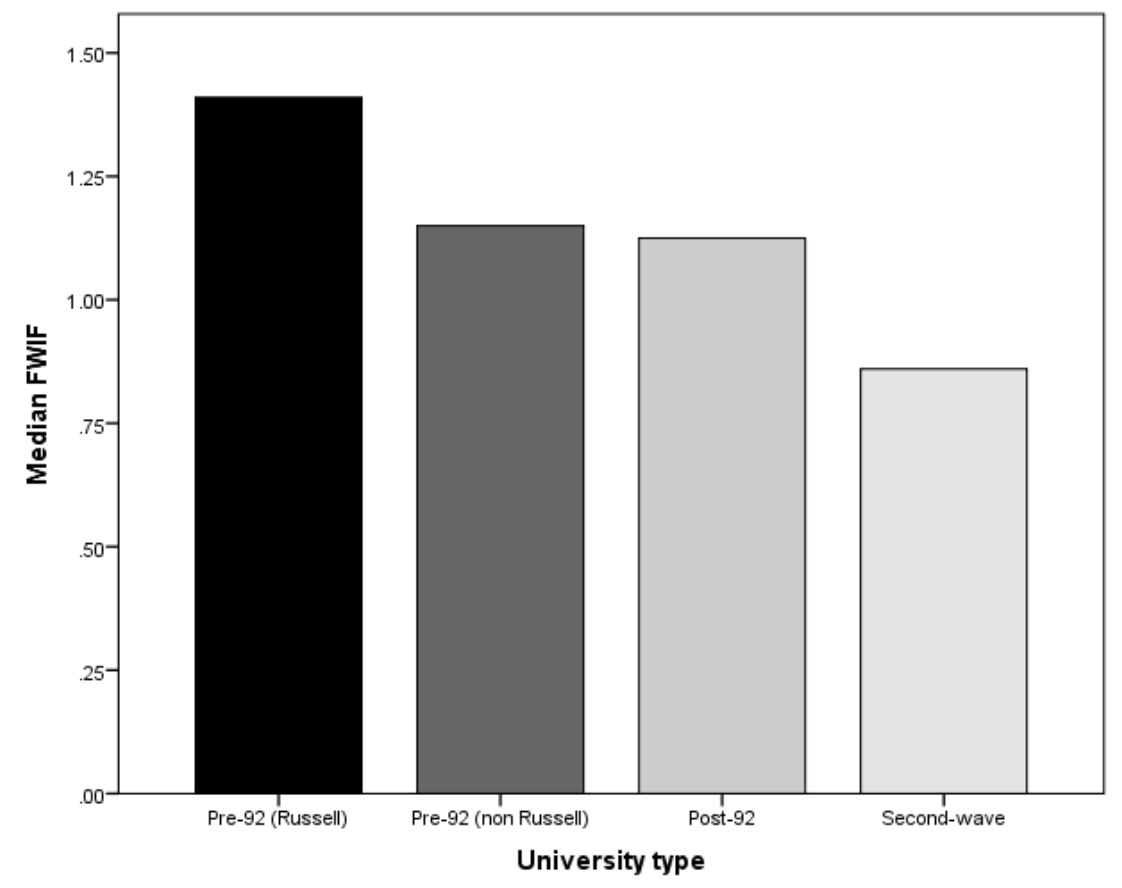

Authors employed at older universities at the time of publication also tend to have a higher $h$-index. The $h$-index scores for lead authors of articles included in the sample were examined using the non-parametric Kruskal-Wallis test to see whether university type (pre-92 (Russell group), Pre-92 (non-Russell group), post-92 and second wave) 
predicts $h$-index scores. The results show a difference between university types in the lead author $h$-index scores $\left(\chi^{2}(3, N=713)=67.74, p<.001\right)$ (see figure 4$)$.

Figure 4. Comparing $h$-index scores by university type



In order to explore this further six pairwise comparisons using Mann-Whitney U were conducted using a Bonferroni corrected value of $p=.008$. These confirmed that authors of articles produced at pre-92 Russell Group universities had a significantly higher $h$ index than the pre-92 non-Russell Group $(\mathrm{U}=20585.00, p<.001)$, post-92 $(\mathrm{U}=$ $17958.50, p<.001)$ and post-92 second wave universities $(\mathrm{U}=4721.00, p<.001)$. The pre-92 non-Russell Group universities showed no difference with the post-92 universities $(\mathrm{U}=13522.50, p=.169)$ but had a significantly higher $h$-index than the second wave universities $(\mathrm{U}=3636.00, p<.001)$. Post-92 first wave universities had a higher $h$-index than the second wave universities $(\mathrm{U}=4074.00, p<.001)$

\section{RQ3. How is productivity influenced by region?}


There is regional variation in overall levels of productivity (figure 5). However, the differences shown in the overall productivity by region do not appear on examination of the median productivity per institution per region (figure 6). A formal Kruskal Wallis test of the median scores, with region as the independent variable and number of articles per university as the dependent variable, shows no difference between the regions $\left(\chi^{2}\right.$ $(11, N=96)=5.64, p=.897)$.

Figure 5. Publication productivity (number of articles) by region, 2000-2013

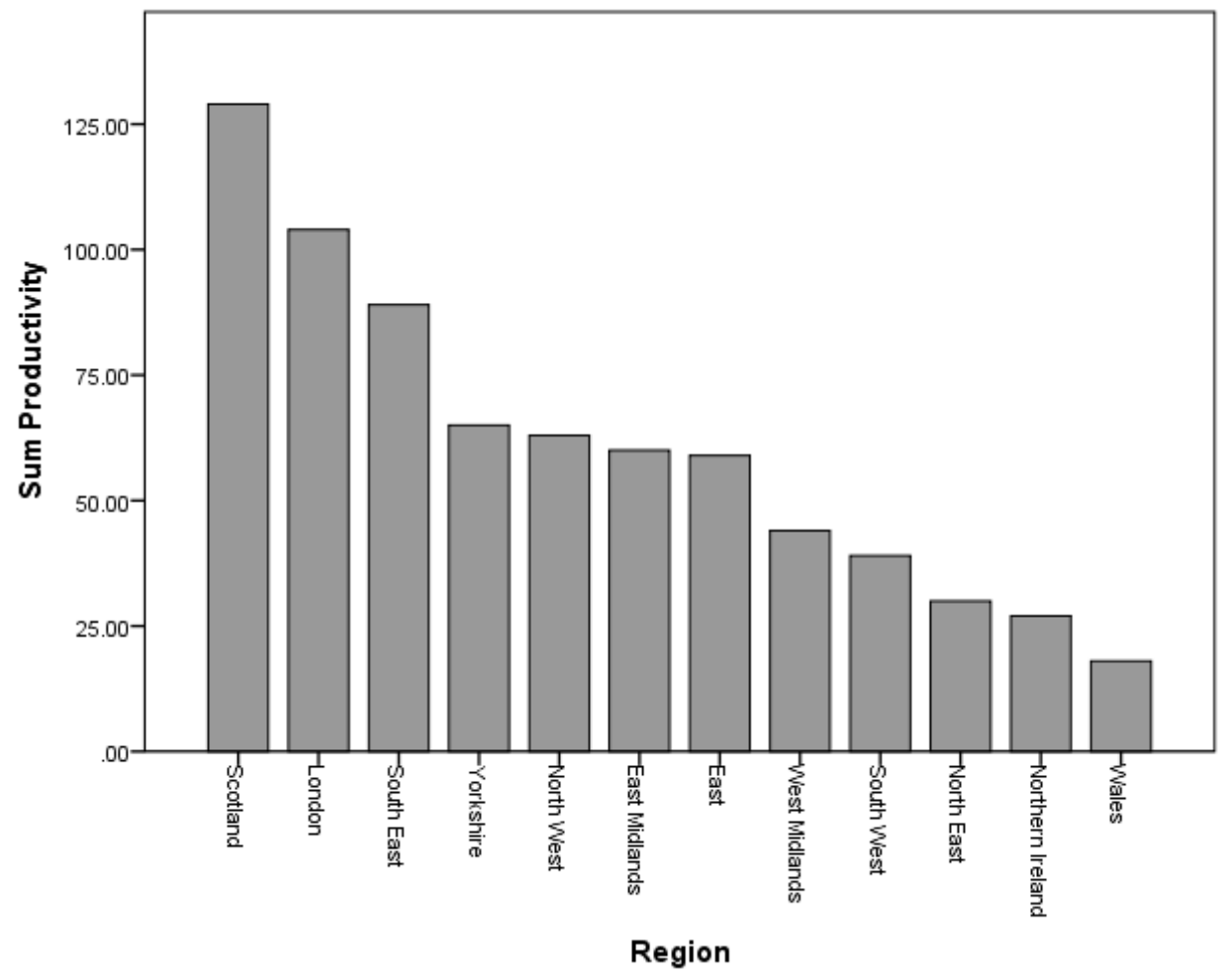

Figure 6. Median productivity per institution by region 


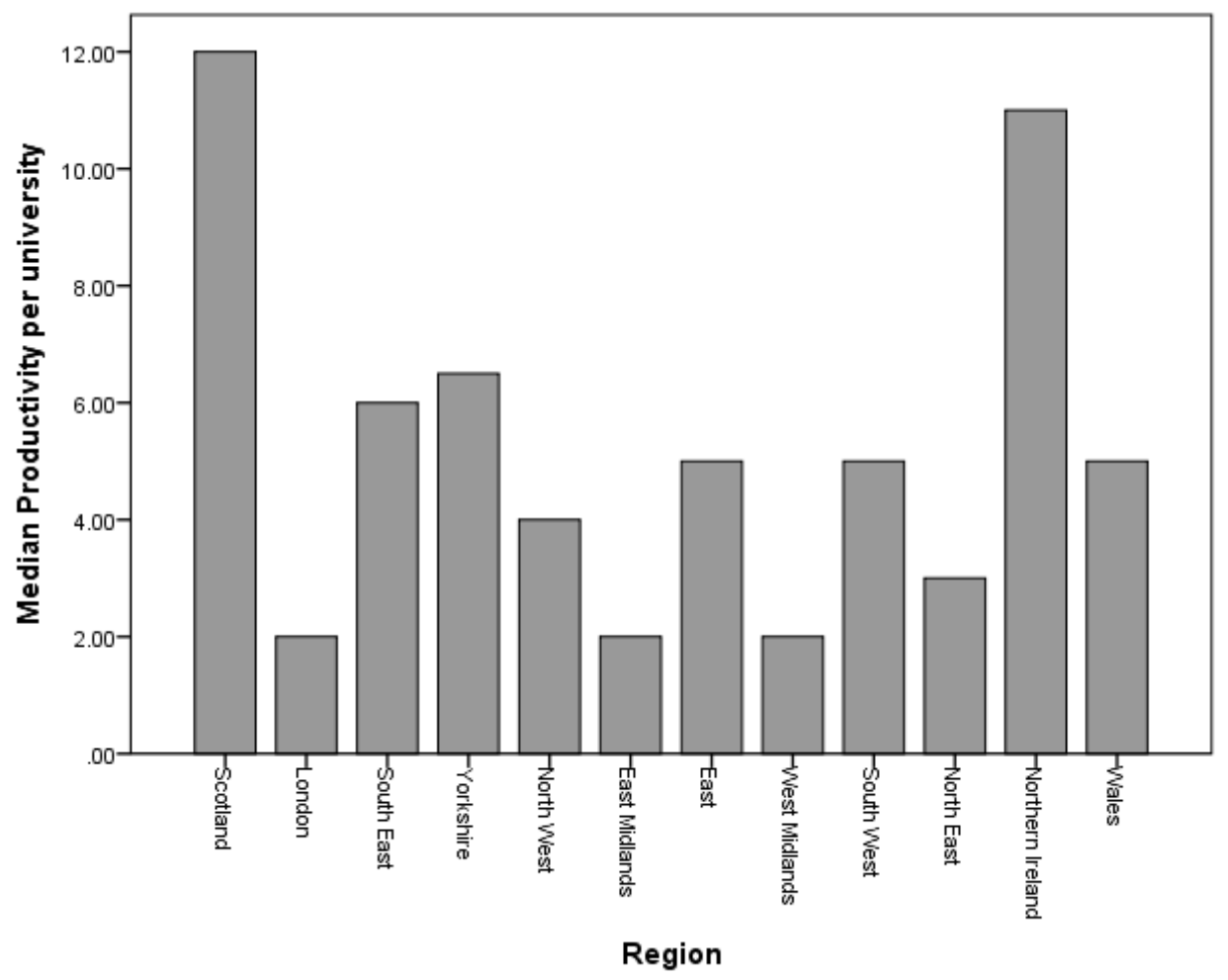

RQ3. What is the association between productivity and the research profile of the institution?

From this analysis, education research returned by university Schools of Education involved in ITE performs well in comparison to overall institutional measures, irrespective of institutional type. Overall there is a moderate, negative significant correlation between RAE 2008 university ranking and the Grade Point Average awarded for Education as a unit of assessment $\left(r_{\mathrm{s}}(66)=-.743, p<.001\right)$ (see figure 7). Similarly, university power ranking in 2014 is strongly positively related to the Education subject ranking in REF $2014\left(r_{\mathrm{s}}(75)=.876, p<.001\right)$ (see figure 8 ).

Figure 7. Comparing RAE 2008 university ranking with the RAE 2008 subject ranking. 


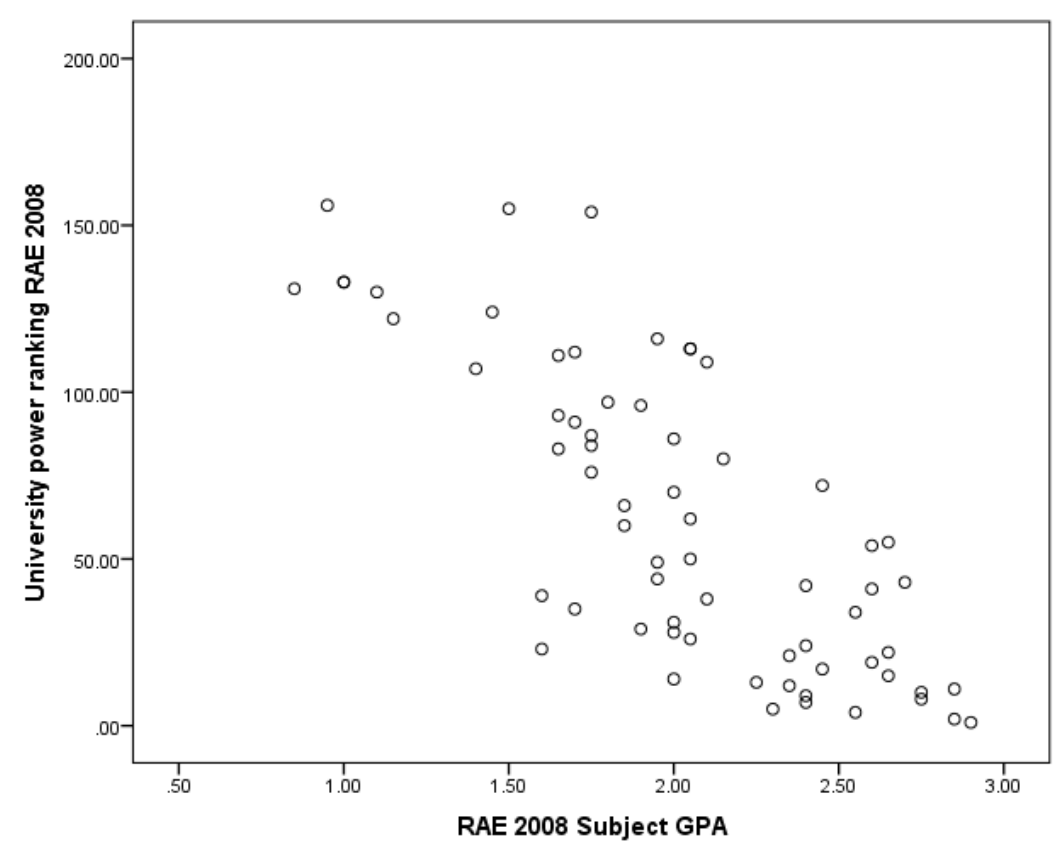

Figure 8. Comparing REF 2014 power ranking with the Education subject ranking

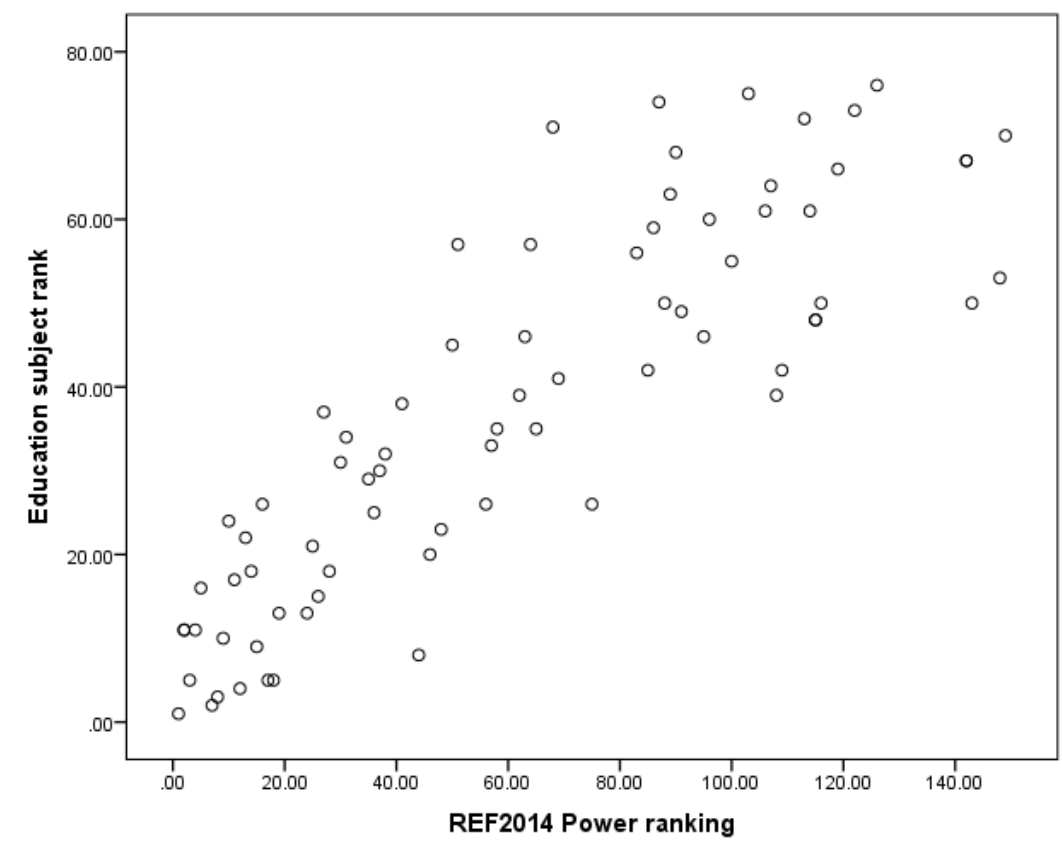

According to this analysis, the size of Schools of Education (in terms of raw faculty numbers) is not associated with the outcomes of research quality assessment. There is no association between the number of research and teaching staff eligible for return in the 
2014 research assessment and the institutional ranking awarded for Education as a unit of assessment for any of the university types (i.e., pre-92 (Russell), pre-92 (non-Russell), post-92, second wave) (all p’s > .05) (figure 9).

Figure 9. Comparing the subject ranking from REF 2014 against the number of staff eligible to be returned in the REF



However, there is marked difference between the different types of HEI and the proportion of eligible staff actually returned in Education submissions for the 2014 REF (figure 10). A Kruskal-Wallis test examining whether there was a difference in the percentage of eligible staff returned on the REF 2014 showed a significant result ( $\chi 2$ (3, $N=75)=37.72, p<.001)$. In order to examine this effect in more detail we ran 6 pairwise comparison using Mann-Whitney U tests with a Bonferroni corrected value of $p=.008$. These showed that Pre-92 Russell Group universities had a higher percentage of staff returned in the REF 2014 than pre-92 non-Russell $(U=70.50, p=.006)$, post-92 $(\mathrm{U}=14.00, \mathrm{p}<.001)$ and second-wave $(\mathrm{U}=3.00, \mathrm{p}<.001)$ universities. Pre-92 non- 
Russell Group universities also had a higher percentage of REF returned staff than post$92(\mathrm{U}=93.50, \mathrm{p}=.005)$ and second-wave universities $(\mathrm{U}=57.00, \mathrm{p}=.002)$. There was no significant difference between post-92 first and second-wave $(U=186.00, p=.794)$.

Figure 10. Comparing median number of staff submitted to the REF 2014 by type of university.

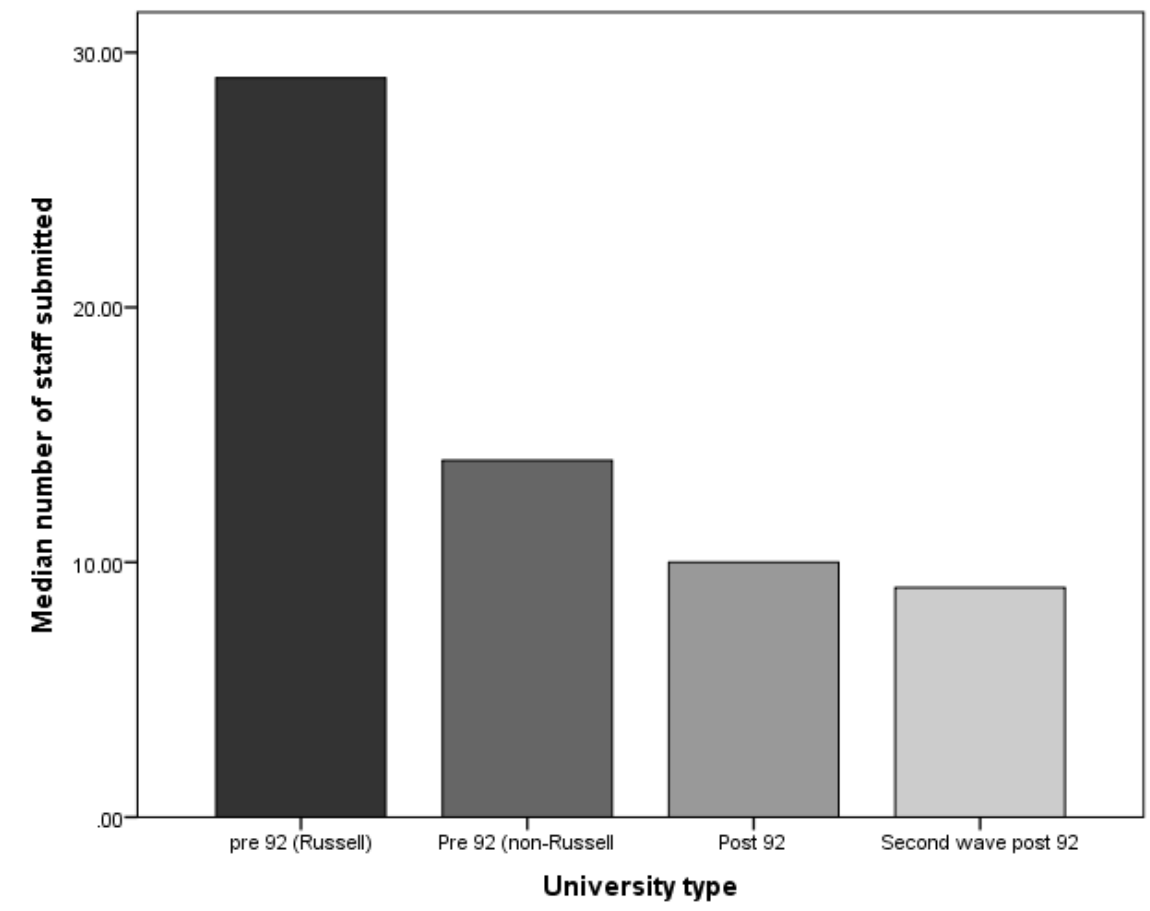

Among UK pre-92 universities $(n=34), 82 \%(n=28)$ returned more than half the eligible staff, and $42 \%(n=14)$ more than three-quarters. In contrast, only $17 \%(n=4)$ of post-92 institutions ( $\mathrm{n}=23$ ) returned over half the number of eligible staff; $74 \%$ (17) returned under a quarter of eligible staff, $22 \%$ (5) less than $10 \%$ of eligible staff. Among the 17 second-wave post-92 institutions, all bar one returned under $50 \%$ of eligible staff. Eighty two per cent (14) returned under a quarter of eligible staff. 


\section{RQ4. How is productivity linked to institutional involvement in initial teacher education?}

This analysis suggests an association between the scale of involvement in teacher education (represented by the annual intake of students to initial teacher education courses) and the REF 2014 subject rank order. Spearman's rank correlations showed a small, marginally significant positive correlation between Education subject ranking and number of trainees admitted to ITE programmes $\left(\mathrm{r}_{\mathrm{s}}(69)=.214, p=.077\right)$ (figure 11). This implies that as the number of trainees increased so did the subject ranking position for Education research. However, when broken down into pre-92 Russell, pre92 non-Russell, post-92, and second wave there were no significant correlations between subject rank and number of trainees ( $p$ 's $>.05)$.

Figure 11. Comparing REF 2014 subject rankings and number of first year trainees by type of HEI

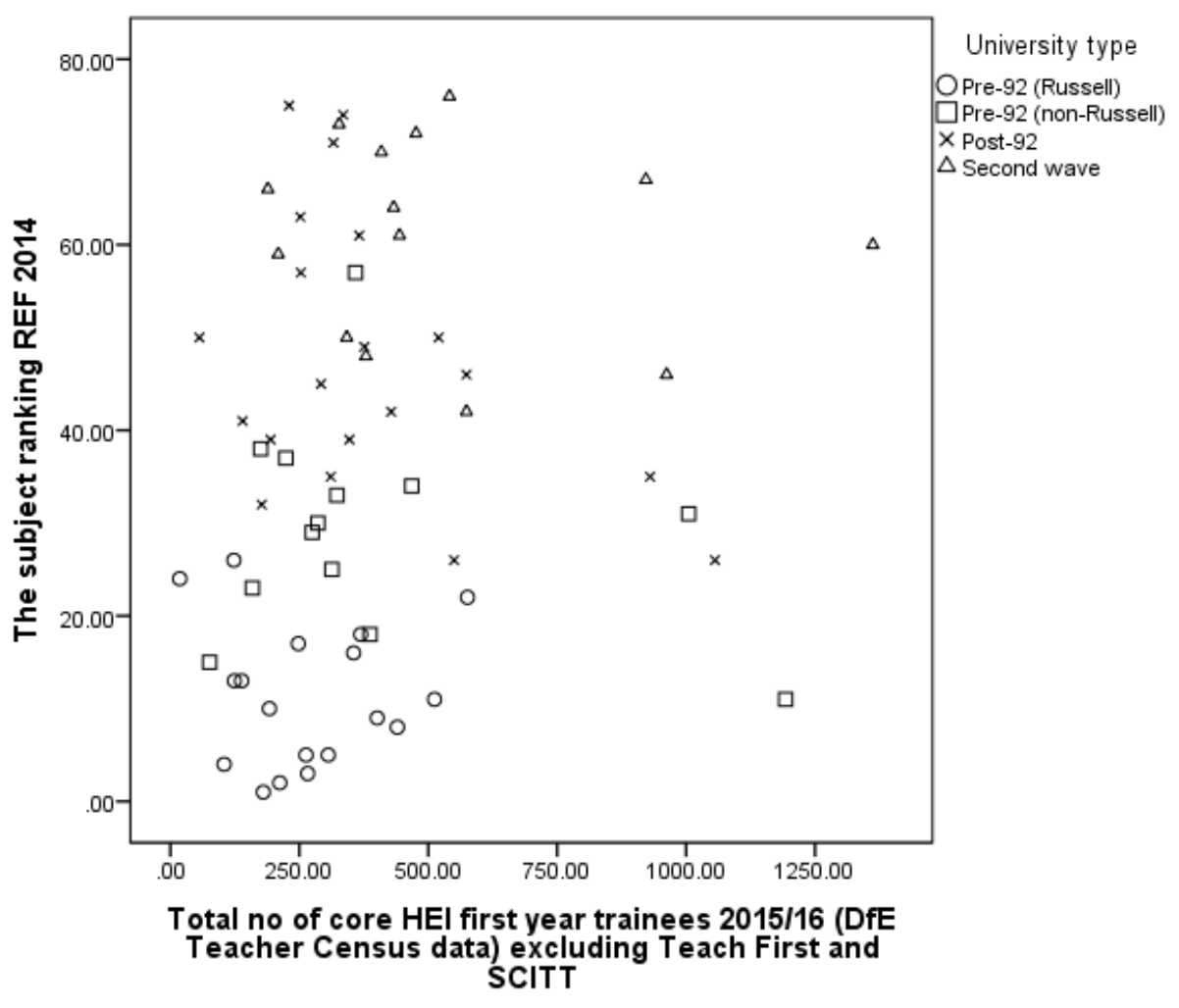




\section{Conclusion}

The above analysis of publication outputs in the field of teacher education raises a number of issues regarding the value and utility of bibliometrics in research assessment and faculty appraisal. The use of bibliometrics rests on the reliability of the data in terms of consistency and coverage, and the validity (and ethicality) of indicators of research quality and scholarly impact. It is noteworthy that of the 39 journals identified as important by the Teacher Education Group (TEG), only 19 are registered with Web of Science and of the 37 registered with Scopus coverage across the period 2000-2013 is incomplete (appendix 1). While author attribution has improved with the incorporation of 16-digit ORCID identifiers (Open Researcher and Contributor ID), controversies abound with regard to citation practices and the use and misuse of ubiquitous measures such as the journal impact factor and $h$-index. The UK Forum for Responsible Metrics $(2017$, p.4) recommended that REF2021 should not make use of journal impact factors and cautious use of citation data on a paper-by-paper basis. Bibliometric analyses valorise particular forms of information above others, strengthening their normative value. Given the political utility of ranking in research governance, it is important to interrogate the claims to authority assembled through metrics. In this analysis, a critically reflexive stance was maintained by approaching research assessment as social practice; and extending the analysis to consider the environment in which articles are produced.

With due consideration to the caveats noted above, a number of claims can be supported by this exploratory analysis. The number of articles published rose rapidly before the $2008 \mathrm{RAE}$, especially in young universities with a lower number of active researchers, and has remained relatively stable since. Using metrics-based indicators of productivity and quality, knowledge production between 2000 and 2013 appears 
modest. Productivity, in terms of the volume of articles per lead author and the fieldweighted citation impact $($ FWCI) of individual articles, is low $(<2)$. Almost half the lead authors $(48 \%)$ produced just one paper in the selected journals over a fourteen-year period. Research activity leading to publication is concentrated in particular sites. Productivity is strongly associated with institutional type, reproducing established patterns of research power. Few Schools of Education were able to exceed the overall research power ranking of their institution. Academics located at pre-1992 universities published a higher volume of research outputs, and outputs that were received more favourably by the research community (in terms of citation). The analysis indicates the continued dominance of a small number of research-intensive universities as producers of research about teacher education, although not necessarily engaged in teacher education on a large-scale. The publication patterns produced in this analysis indicate the difficulty of building and maintaining a research profile in teacher education. This appears particularly acute in post-92 institutions where the majority of teacher preparation programmes are located. This supports the view of Andrew Pollard, REF 2014 Education sub-panel chair, that,

The activity required to compete successfully in social scientific terms is becoming increasingly distinct from the activity required to flourish in the rapidly changing fields of teacher education. The pressure which this puts on staff working in Education is sometimes extremely acute. (Pollard 2014, p.2)

Institutional research strategies informed by evaluative bibliometrics are likely to strengthen the boundaries between the activities of research and teaching. The small concentrations of research active faculty found in this study limits the potential for sector-wide capacity building. Moreover, assessments of impact that over-emphasise metrics may yield little insight into the relation of end-users to research in professional 
education. Only 13 of the 215 impact case studies submitted by UK HEIs to Education (Unit of Assessment 25) for REF 2014 make explicit reference to Initial Teacher Education (ITE) in the text of their submission (Grant and Hinrichs, 2015). The expansion of open access journals charging article processing fees is a further challenge to academics in the field of teacher education, which has a lower record of grant capture (to cover fees) and a higher concentration of faculty in Schools of Education with lower allocations of block grants to support moves towards open access. Such developments may further inhibit the development of strong research cultures within Schools of professional education. At a departmental level, a low rate of productivity per academic would have had consequences had Recommendation One of the Stern Review, Building on Success and Learning from Experience (Department of Business, Energy and Industrial Strategy, 2016, p.19), been fully implemented: 'All research active staff should be returned in the REF'. The requirement for 'all staff with significant responsibility for research' to be returned affords submitting institutions a degree of flexibility (REF 2017, p.3). Aspirations for research-informed teacher education and the promotion of research literacy among all educators (BERA RSA, 2014) are likely to be adversely affected by increased selectivity. Education had the largest proportion of small submissions to REF 2014 with 48/76 involving fewer than 15 staff. Moreover, the volume of lowest ranked $1 *$ work in Education was among the highest of all the units of assessment; $7 \%$ compared with 3\% across the whole REF.

Within this challenging context, more work is needed to explore the factors contributing to successful writing collaborations and effective research governance, including institutional mission statements, priorities for research and research cultures and practices. Research capability in Education is growing. The volume of highest ranked outputs doubled from $15 \%$ in 2008 to $30 \%$ in 2014 . This preliminary analysis of 
factors influencing publication in teacher education research might usefully be expanded to focus on connections among the community of scholars that constitute the field. Social network theory has much to offer in exploring the links between researchers and their activities (West and Vilhena, 2014; Leydesdorff, 2014). Citation networks and co-authorship networks have the potential to provide important insights into the travel of ideas and developments over time. Mapping may also be used to identify and explore effective institutional research and knowledge exchange strategies, particularly within full service Schools of Education. While citation remains a proxy for impact, evaluations of scholarly productivity need to include context-sensitive estimates that acknowledge research as social practice. These might usefully include: (i) altmetrics that acknowledge more than one publication genre and the increased levels of interactivity afforded by digital technologies; (ii) systems for recording and acknowledging the 'second-order contributions' of colleagues involved in 'subauthorship collaboration' (Cronin 2014, p.4); (iii) wider definitions of scholarly impact that valorise academic citizenship e.g. contributions to mentoring early career researchers who may be experienced educators; and (iv) usage-based metrics that include contributions to curriculum development, practice enhancement and national policy formation. Such deliberation is important in promoting research-rich programmes of professional preparation, across institutional types, in an era of metricsrich performance evaluation.

\section{References}

van Arensbergen, P., van der Weijden, I. \& van den Besselaar, P. 2012. “Gender differences in scientific productivity: a persisting phenomenon?" Scientometrics, 93(3): 857-868.

Avalos, B. 2011. "Teacher professional development in Teaching and Teacher Education over ten years". Teaching and Teacher Education, 27(1): 10-20. 
Barnes, C. 2014. "The emperor's new clothes: the h-index as a guide to resource allocation in higher education" Journal of Higher Education Policy and Management, 36(5): 456-470.

Barnes, C. 2015. "The Use of Altmetrics as a Tool for Measuring Research Impact" Australian Academic \& Research Libraries, 46(2): 121-134

Beauchamp, G., Clarke, L., Hulme, M., Jephcote, M., Kennedy, A., Magennis, G., Menter, I., Murray, J., Mutton, T., O'Doherty, T. \& Peiser, G. 2015. Teacher Education in Times of Change. Bristol: Policy Press.

BERA 2015. Education Research in 2015. https://www.bera.ac.uk/promotingeducational-research/projects/bera-observatory Accessed 23 March 2018.

BERA-RSA 2014. Research and the Teaching Profession, London: BERA.

Burrows, R. 2012. "Living with the h-index? Metric assemblages in the contemporary academy" The Sociological Review, 60(2): 355-372.

Butler, I. 2007. “Assessing university research: A plea for a balanced approach" Science and Public Policy, 34(8): 565-574.

Cochran-Smith, M. \& Villegas, A.M. 2015. "Framing Teacher Preparation Research: An Overview of the Field, Part 1" Journal of Teacher Education, 66(1): 7-20.

Colwell, R., Blouw, M., Butler, I., Cozzens, S.E., Feller, I., Gingras, Y. \& Woodward, R. 2012. Informing Research Choices: Indicators and Judgement. Ottawa: Expert Panel on Science Performance and Research Funding.

Cronin, B. 2014. "Scholars and Scripts, Spoors and Scores" In Beyond Bibliometrics. Harnessing Multidimensional Indicators of Scholarly Impact. Edited by Cronin, B. \& Sugimoto, C.R. Cambridge MA: MIT Press, pp. 3-22.

Department of Business, Energy and Industrial Strategy 2016. Building on Success and Learning from Experience. An Independent Review of the Research Excellence Framework. https://www.gov.uk/government/uploads/system/uploads/attachment data/file/5 41338/ind-16-9-ref-stern-review.pdf Accessed 23 March 2018.

Diem, A. and Wolter, S.C. 2013. "The Use of Bibliometrics to Measure Research Performance in Education Sciences" Research in Higher Education, 54(1): 86114.

Forum for Responsible Research Metrics 2017. Metrics in REF2021: Advice from the UK Forum for Responsible Research Metrics. 
http://www.universitiesuk.ac.uk/policy-and-analysis/Documents/forum-forresponsible-research-metrics-response-to-REFconsultation2017.pdf Accessed 23 March 2018.

Gingras, Y. 2014. "Criteria for Evaluating Indicators” In Beyond Bibliometrics. Harnessing Multidimensional Indicators of Scholarly Impact. Edited by Cronin, B. \& Sugimoto, C.R. Cambridge MA: MIT Press, pp. 109-126.

Gogolin, I., Aström, F. \& Hansen, A. 2014. Assessing Quality in European Educational Research: Indicators and Approaches, Wiesbaden: Springer.

Grant, J., Brutscher, P.B., Kirk, S.E., Butler, L. \& Wooding, S. 2010. Capturing research impacts: A review of international practice, Cambridge: Higher Education Funding Council for England.

Grant, J., \& Hinrichs, S. 2015. The nature, scale and beneficiaries of research impact: An initial analysis of the Research Excellence Framework (REF) 2014 impact case studies. London, Higher Education Funding Council for England.

Greenberg, S. A. 2009. "How citation distortions create unfounded authority" British Medical Journal, 339: b2680.

Hicks, D. 2012. "Performance-based university research funding systems" Research Policy, 41(2): 251-261.

Hicks, D. 2013. "One size doesn't fit all: On the co-evolution of national evaluation systems and social science publishing" Confero: Essays on Education, Philosophy and Politics, 1: 67-90.

Higher Education Statistics Agency 2015. Contextual data for the Research Excellence Framework 2014. https://www.hesa.ac.uk/dox/pressOffice/sfr209/290183_REF_Contextual_table 1314.xlsx Accessed 25 May 2016.

Hirsch, J.E. 2005. “An index to quantify an individual's scientific research output" Proceedings of the National Academy of Sciences, 102: 16569-16572.

Kousha, K. \& Thelwall, M. 2007. "Google Scholar citations and Google Web/URL citations: A multi-discipline exploratory analysis" Journal of the American Society for Information Science and Technology, 58(7): 1055-1065.

Larsson, S. 2009. "An emerging economy of publications and citations" Nordisk Pedagogik, 29: 34-52. 
Leydesdorff, L. 2014. "Science Visualisation and Discursive Knowledge” In Beyond Bibliometrics. Harnessing Multidimensional Indicators of Scholarly Impact Edited by Cronin, B. \& Sugimoto, C.R. Cambridge MA, MIT Press, pp.167-186. Lindgren, L. 2011. "If Robert Merton said it, it must be true: A citation analysis in the field of performance measurement" Evaluation, 17(1): 7-19.

McNamara, O. \& Murray, J. 2013. The School Direct programme and its implications for research informed teacher education and teacher educators. York: Higher Education Academy.

Menter, I., Hulme, M., Murray, J., Campbell, A., Hextall, I., Jones, M., Mahony, P., Procter, R. \& Wall, K. 2010. "Teacher education research in the UK: the state of the art" Revue Suisse des sciences de l'education, 32(1): 121-142.

Menter, I. 2011. 'Four 'academic sub-tribes', but one territory? Teacher educators and teacher education in Scotland" Journal of Education for Teaching, 37(3): 293308.

Menter, I., Hulme, M. \& Sangster, P. 2012. "Performance in teacher education and research - a double whammy for teacher educators?" In Performativity in the UK Education System: Ethnographic cases of its effects, agency and reconstructions. Edited by Jeffrey, B. \& Troman, G. Ethnography \& Education Publishing: Stroud, pp. 23-40.

Mignolo, W. 2013. "Geopolitics of sensing and knowing: On (de) colonialists, border thinking and epistemic disobedience" Confero: Essays on Education Philosophy and Politics, Vol. 1: 129-150.

Murray, J., A. Campbell, I. Hextall, M. Hulme, M. Jones, P. Mahony, I. Menter, R. Procter \& K. Wall. 2008. "Mapping the Field of Teacher Education Research: methodology and issues in a research capacity building initiative in teacher education in the United Kingdom" European Educational Research Journal, 7(4): 459-474.

Nylander, E., Aman, R., Hallqvist, A.,Malmquist, A. \& Sandberg, F. (2013) “Managing by measuring: Academic knowledge production under the ranks" Confero: Essays on Education Philosophy and Politics, Vol. 1: 5-18.

Oancea, A. and Mills, D. 2015. The BERA Observatory of Educational Research. https://www.bera.ac.uk/wp-content/uploads/2014/08/BERA-ObservatoryFINAL.pdf Accessed 9 October 2018. 
Pollard, A. 2014. REF 2014: What does it mean for education?

https://www.bera.ac.uk/wp-content/uploads/2014/12/REF-BERA-

Commentary.pdf Accessed 9 0ctober2018.

REF 2014. Research Excellence Framework. https://www.ref.ac.uk/2014/ Accessed 23 July 2019.

REF 2017. REF 2021 Decisions on staff and outputs.

https://www.ref.ac.uk/media/ref,2021/downloads/REF\%202017_04\%20Decisio ns\%2023.11.2017.pdf Accessed 26 March 2018.

Sarkozy, A., Slyman, A. \& Wu, W. 2015. "Capturing Citation Activity in Three Health Sciences Departments” Medical Reference Services Quarterly, 34(2): 190-201.

Thelwall, M. \& Delgado, M.M. 2015. “Arts and humanities research evaluation: no metrics please, just data” Journal of Documentation, 71(4): 817-833.

The Russell Group of Universities, 2017. Profile.

https://russellgroup.ac.uk/media/5524/rg text june2017_updated.pdf Accessed 7 January 2019.

West, J.D. \& Vilhena, D.A. 2014. “A Network Approach to Scholarly Evaluation” In Beyond Bibliometrics. Harnessing Multidimensional Indicators of Scholarly Impact. Edited by Cronin, B. \& Sugimoto, C.R. Cambridge MA: MIT Press, pp.151-166.

Whitty, G., Donoghue, M., Christie, D., Kirk, G., Menter, 1., McNamara, 0., Moss, G., Oancea, A., Rogers, C. \& Thompson, P. 2012. Prospects for Education Research in Education Departments in Higher Education Institutions in the UK, London: BERA \& UCET.

Wilsdon, J., Allen, L., Belfiore, E., Campbell, P., Curry, S., Hill, S., Jones, R., Kain, R., Kerridge, S., Thelwall, M., Tinkler, J., Viney, I., Wouters, P., Hill, J. \& Johnson, B. 2015. The Metric Tide: Report of the Independent Review of the Role of Metrics in Research Assessment and Management, London: HEFCE.

Wyse, D., Brown, C., Oliver, S. \& Poblete, X. 2018. The BERA Close-to-Practice Research Project: Research Report. London: British Educational Research Association. https://www.bera.ac.uk/researchers-resources/publications/berastatement-on-close-topractice-research Accessed 4th January 2019. 


\section{Appendix 1: Scopus coverage}

\section{Journals with complete coverage in SCOPUS 2000-2013}

1. British Educational Research Journal, from 1996

2. British Journal of Educational Studies, from 1996

3. British Journal of Sociology of Education, from 1995

4. Disability and Society, from 1995

5. Educational Research, from 1996

6. Educational Review from 1996

7. Educational Studies, from 1996

8. Gender and Education, from 1996

9. International Journal of Educational Research, from 1986

10. Journal of Education Policy, from 1996

11. Oxford Review of Education, 1996

12. Teachers and Teaching: Theory and Practice, from 1996

13. Teaching and Teacher Education from 1985

14. Professional Development in Education has complete coverage under its new name (previously Journal of In-service Education) from 2009+

\section{Journals with incomplete coverage in SCOPUS 2000-2013}

1. Cambridge Journal of Education, 1971-1995, then from 2005+

2. Educational Action Research, 1993-1999, then 2007+

3. Educational Philosophy \& Theory, from 2008+

4. Educational Research and Evaluation, from 2005+

5. European Journal of Educational Research, 1982-1995, then from 2005+

6. European Journal of Teacher Education, 1982- 1995 then from 2005+

7. Higher Education Quarterly, 2008+

8. International Journal of Research and Method in Education, from 2005+

9. International Studies in Sociology of Education, 1992-1995, then 2007+.

10. Irish Educational Studies 1981-1995, then from 2008+;

11. Journal of Education and Work, from 2005+

12. Journal of Education for Teaching, from 1996 to 1998, from 2001 to 2003, from 2005+

13. Journal of Further \& Higher Education 1978-1995, then 2010+;

14. Journal of In-Service Education only available on Scopus for 2007 and 2008 and not earlier;

15. Journal of Vocational Education and Training from 2010+;

16. Management in Education, from 2008+

17. Mentoring and Tutoring: Partnership in Learning just 1995 then from 2010+;

18. Pedagogy Culture and Society from 2007+

19. Research in Education, from $2007+$

20. Research in Post-Compulsory Education, 2007+

21. Research Papers in Education 1986-1995, then 2010+;

22. Teacher Development, 2007+

23. The Curriculum Journal only 1990-1995; 2010+

\section{Journals with no coverage in SCOPUS 2000-2013}

1. Scottish Educational Review

2. Higher Education Review 